\title{
Native versus Nonnative: A Literacy Teacher Educator's Story
}

\author{
CHEU-JEY LEE \\ Indiana University-Purdue University Fort Wayne
}

In the English language teaching (ELT) profession, NNEST is an acronym for nonnative English-speaking teachers, that is, English language teachers who speak English as a second or foreign language. NEST, in contrast, stands for native English-speaking teachers or those who speak English as their first or native language. The dichotomy between NNEST and NEST, though intuitively appealing at first glance, has been debated for years (Kachru, 1992; Liu, 1999; Medgyes, 1994). According to Maum (2002), proponents of the dichotomy believe that it is necessary to distinguish between native and nonnative English-speaking teachers because their differences should be recognized. Those who oppose the dichotomy argue that differentiating between teachers based on their linguistic status rather than competence perpetuates the dominance of the native speaker in the ELT profession. For example, studies (Amin, 2000; Braine, 1999; Canagarajah, 1999) show that native English speakers without teaching qualifications are more likely to be hired than qualified and experienced NNESTs, especially outside the United States. Phillipson $(1992,1996)$ uses the phrase "the native speaker fallacy" (the belief that the ideal teacher of English is a native speaker) to refer to unfair treatment of qualified NNESTs. Canagarajah (1999) follows suit by interrogating and dismantling the fallacy from the linguistic, political, and economic slant. The debate on the dichotomy has also led to more research on the careers of NNESTs (Johnston, 1997) and the power, race, and identity of NNESTs (Amin, 1997; Shuck, 2006; Tang, 1997). A central theme recurring in these studies is that NNESTs should not be marginalized as secondary to NESTs but regarded as equal peers and contributors in the ELT profession.

In 1998, TESOL, an international professional association that represents teachers of English to speakers of other languages, approved the formation of the NNEST Caucus.1 Ever since, according to Matsuda (2002), "NNEST has become one of the most visible topics at TESOL conventions, and NNEST sessions and open meetings continue to attract a growing number of TESOL professionals - both NNESTs and NESTs alike" (p. 1). Matsuda goes on to proclaim that "NNEST is more than just a Caucus; it's a movement" (p.1).

Though the NNEST movement has been successful in raising an awareness of the importance of NNESTs, it is set mainly in the context of teaching and learning English as a second or foreign language (ESL or EFL). Most of the existing NNEST literature is concerned with the investigations of NNESTs as English language teachers in relation to their counterparts as native English speakers as well as to their students as nonnative English speakers. It hardly addresses the issues of NNESTs teaching native English speakers in the context of a teacher education program. Specifically, there is no shortage of accounts of native speakers teaching English as a second or foreign language to nonnative speakers or nonnative speakers teaching English to speakers of other languages. Yet there is a dearth of stories in the literature that portray the relationship between NNESTs and their native English-speaking students. The story I 
am about to tell is concerned with a nonnative English-speaking (NNES) teacher educator working with native English-speaking (NES) pre- and in-service teachers in the field of literacy education at a university in the United States. It is a story fraught with doubts, struggles, and lessons to be learned.

\section{Theoretical Framework: a Subjective Story versus an Objective Study}

At first, I was undecided about whether and how to present the story because it concerned my own experience. I felt there to be a tension between a subjective story and an objective study. The former implies something personal while the latter usually means a scientific and verifiable account. Valid knowledge is often referred to as objective rather than subjective. Likewise, findings obtained through an empirical study seemed more reliable than information gleaned from a story. Then why is a subjective account worth telling and listening to? I asked myself. I had to convince myself before presenting it to my audience. At this crossroads, I took heart from thinking about what Habermas and Clandinin and Connelly would say about a subjective story. In what follows, I briefly discuss Habermas's view on subjective knowledge versus objective knowledge as well as Clandinin and Connelly's view on a study versus a story as their insights hint at the value of exploring a personal narrative

\section{Subjective versus Objective}

For Habermas (1971), one of the most influential contemporary philosophers, subjective knowledge and objective knowledge are both important. They are simply categorically different. Instead of truth or knowledge, Habermas $(1984,1987)$ uses validity claims to emphasize the communicative origins of truth and other related concepts. He argues that each meaningful act internally references or carries validity claims which are subject to validation between interlocutors. Objective claims are those to which one has multiple access while subjective claims are open only to privileged access. Consider, for example, that I am in a meeting with someone when I look out the window and see a tree. I then turn to the person beside me and said, "Look at that tree. Isn't it beautiful?" At least two kinds of claims are embedded in my statement. First, I claimed that there was a tree outside the window. This was an objective claim. It was open to multiple access. That is, the person could certainly look out the window and see if there was a tree. Or we could even invite a third person or more people to check if there was a tree outside the window. The second claim implied in my statement was a subjective claim. The person might have thought that I must have liked the tree to comment that it was beautiful. Yet the phrase "must have liked" suggests that it was only a guess. I was the only person that knew whether I liked the tree or not - only I had privileged access to what I said.

While Habermas's theory is certainly much broader and deeper, a brief discussion of his ideas about validity claims serves to explain why a subjective account is also important. It is not simply about what one does but also how s/he feels about it. It is something personal but can be shared through, for example, story-telling. If Habermas is right (i.e., if subjective knowledge is as important as objective knowledge), then there are experiences in the subjective domain that cannot be tapped into through an objective lens.

\section{A Study versus a Story}

Clandinin and Connelly (e.g., see Clandinin, 2007; Clandinin \& Connelly, 1994, 1996; Connelly \& Clandinin, 1990) propose that people's experiences can be studied through the stories they live and tell. Following Dewey and Carr, Clandinin and Connelly (1994) argue that 
people note something of their experience to themselves or to others not by merely recording it but recounting it in storied form. They go on to stress that:

In effect, stories are the closest we can come to experience, as we and others tell of our experience. A story has a sense of being full, a sense of coming out of a personal and social history. With this as our standpoint, we have a point of reference, a life and ground to stand on, for both imagining what experience is and imagining how it might be studied and represented in researchers' texts. Experience, in this view, is the stories people live. (p. 415)

Clandinin and Connelly call their approach to studying experience "narrative inquiry." By this, they mean that "narrative is both phenomenon and method" (p. 416). In other words, research conducted in storied form is argued to be a valid study of approaching one's lived experience.

Built on Habermas's insight, this paper is intended to explore the subjective domain of my teaching experience that cannot be fully captured through an objective lens. In addition, the exploration is documented in storied form proposed by Clandinin and Connelly. It is not simply a description of my story but a critical reflection on my lived experience regarding its meaning and significance to me and others as well. That is, in Clandinin and Connelly's (1994) language, the story is both a "field text" and a "research text" (p. 423). In what follows, I will divide my story into two parts: pre-teaching and post-teaching. It is about the journey before and after I became a teacher educator. It focuses on the interconnection between pedagogical practices and philosophical beliefs. The story also includes a critical reflection on how I reposition myself as a NNES teacher educator. Through this journey, the tension between native and nonnative is cast in a new light and argued to be a positive quality that should be valued in the field of literacy education.

\section{Banking Education}

\section{Pre-teaching}

Could I as a nonnative speaker teach native speakers how to teach literacy? I did not believe so. In fact, never had I thought about it. Even with a doctoral degree in literacy education, I could not steer clear of this spell that was taken for granted and never questioned. I thought the best I could do was to teach English to speakers of other languages. I did not think that I had enough knowledge to pass on to native speakers. Knowledge, I believed, was associated with authority. The more knowledge I had, the more authority I would gain. And to be a competent teacher, I felt I needed to be an authority. Yet I felt my accent prevented me from being an authority. Attaining a doctoral degree in literacy education was hoped to grant me more credibility and confidence. However, it did not seem to work. Though I was not aware of the term at the time, I was totally trapped in the banking concept of education where

Education . . . becomes an act of depositing, in which the students are the depositories and the teacher is the depositor.... In the banking concept of education, knowledge is a gift bestowed by those who consider themselves knowledgeable upon those whom they consider to know nothing. (Freire, 1984, p. 58)

Instead of nothing, my students certainly knew something. In fact, as native speakers, they had knowledge and experience with the language I did not. This was why I did not think I had anything to deposit in them. Actually, I felt disqualified and intimidated to be their teacher or depositor. 


\section{A Safe Harbor}

Fortunately, there was an alternate path to take. For most nonnative speakers, teaching English to speakers of other languages, especially to those of their own language and culture, is probably one of the most chosen careers. Many of the international students I knew in my doctoral program went back to their home countries to teach English after they finished their studies. I was pretty sure this was the route I would take, too. It seemed to be a reasonable choice because teaching English as a second or foreign language in my home country Taiwan is considered a decent job. Learning English is believed (or misbelieved) to be very important for every child as it is becoming a global language and a step stone to success. Children who are able to attend an ESL/EFL program are considered an elite group. Parents with considerable financial resources even send their children abroad to study in an English-speaking country. Consequently, it seemed much easier to teach in my home country than in the United States (though this can be a misconception).

\section{A Battle against Myself}

To my amazement, I was offered a job as a teacher educator in the United States with responsibility for teaching methods courses in literacy/language arts to pre- and in-service teachers (yes, to those native speakers I did not dare to teach). During my job interview, I told myself to look very confident, but my nonstandard accent kept reminding me that there was something wrong about me. Fortunately, the search committee seemed to have more confidence in me than I did in myself, and I was offered the position.

The summer before I began my first semester of teaching was supposed to be the most carefree. I finished my doctoral program. I had a job waiting for me. My family and friends thought I was great and should be very happy. But I had to admit that it was one of the most difficult times I had in my life - a battle against myself. I had to convince myself that I was able to do the job well. It was a battle against my ingrained belief about teaching - essentialism. Essentialists believe that schools should equip students with basic academic skills to survive in society. Teachers are supposed to transmit knowledge to students who usually play a passive role in the process of learning (Bagley, 1934, 1938). Does this ring a bell? Yes, it is reminiscent of the banking education I mentioned previously. I thought I had to have more knowledge than my students did, so that I could pass it on to them. I still remember that I read piles of books that summer. And I spent a considerable amount of time preparing for the courses I was about to teach. I was overwhelmed but did not feel prepared. In fact, what scared me most, though I did not have a clue at that time, were not my future students but the essentialist belief I clung to. It kept telling me to be better than my students. However, as a nonnative speaker, I did not think it could happen. What I needed in order to overcome my fear was a critical examination of my teaching philosophy. Though I was daunted by teaching, it was when I taught that I began to reflect on and question my essentialist belief.

\section{A Critical Incident}

\section{Post-teaching}

The pre-service teachers at my university had to study educational philosophies (essentialism, perennialism, progressivism, and critical theory), examine various philosophies, and reflect on their own philosophies. At the end of the degree program, their philosophy statements along with artifacts (such as lesson plans, papers, projects, etc.) had to be included in their exit portfolios for evaluation. As one of the portfolio evaluators, I had the opportunity to 
read their statements. This prompted me to examine my own philosophical beliefs and their pedagogical implications. I was awakened to the fact that I was an essentialist and practiced deficit-based instruction where I tried to identify and remedy what students could not do rather than to find out and build on what they could do. My students were positioned as "receivers (and victims) of knowledge, not creators" (Campano, 2008, p. 145). As an essentialist, I had to know more than my students did. Yet as a nonnative speaker, I did not believe I was more knowledgeable. Hence, the essentialist mindset limited my students' potential to learn on the one hand and put me in a self-contradictory dilemma on the other hand.

\section{From Essentialism to Praxis}

How about escaping essentialism? It sounds enticing but is certainly not easy. Praxis, which consists of reflection and action, is the term that best captures what I experienced. Freire is probably the most prominent educator that advocates praxis and implements it as well in literacy education. Here is how he interprets praxis:

As we attempt to analyze dialogue as a human phenomenon, we discover something which is the essence of dialogue itself: the word.... Within the word we find two dimensions, reflection and action, in such radical interaction that if one is sacrificed - even in part - the other immediately suffers. There is no true word that is not at the same time a praxis (Freire, 1984, p. 75 , italics in original).

Dialogue plays a central role in Freire's pedagogy. The essence of dialogue is the word that contains both reflection and action. For Freire, praxis is a true word that can transform the world. As a result, praxis is both reflection and action; it is a dialectic, a continuous back-and-forth interaction, between reflection and action. Freire emphasizes that reflection cannot be alone without action; otherwise, it becomes verbalism. Similarly, action without reflection is lopsided and reduced to activism. Neither verbalism nor activism is a true praxis. Only dialogue along with both reflection and action comprises an authentic praxis.

Progressively I have replaced the vacuum left by essentialism with Freire's concept of praxis which has served as a constant reminder about the role I should play as a teacher educator. This change did not happen all of a sudden. Instead of a paradigm shift, it was a continuous dialectic. I heard about and actually studied the concept of praxis when I was a student but did not understand it until I had to teach in the university setting. Carspecken (1999) argues that people need to act in order to understand, and that is the very essence of praxis. I have learned to reflect on what I teach and then take action to change my teaching. Sometimes, action has to be attempted before reflection. I have to act based on my best understandings at the time though I may not have a perfect understanding. This is akin to the attitude a critical inquirer might have: "Believing most of what we know to be right allows us to act, but knowing one tenet is wrong and not being sure of which tenet it is allows us to learn" (Harste, 2008, p. 35).

\section{Power Relations}

Power relations must be considered in tangent with praxis. I am satisfied with the dialogical interaction with students. But how should I position myself in relation to students? Switching from an essentialist to a praxis perspective, I am no longer an authority over my students. Then what is my role? This is where power relations come into play. Can power relations be equalized between my students and me while at the same time both of us are empowered? Does that mean I can use my authority as a teacher to check and balance my students' power as native speakers and vice versa? Power relations are another riddle that has to 
be solved. In what follows, I will discuss two kinds of power that supplement the concept of praxis.

\section{External power}

When power is regarded as a force located outside a dialogical process oriented toward reaching understanding, it is an external condition of the dialogue. Therefore, it is called external power. It is what Carspecken (1999) refers to as coercive power or coercion in communicative action. External power should be neutralized or the dialogue will be distorted. Suppose, for instance, someone asks me to read a paper she has worked on. After a couple of weeks when we met, the person inquires excitingly, "What did you think about my paper?" Seeing me remain silent, the person adds, "It was the third revision I made. Hopefully, it would be accepted this time." Showing impatience, I comment, "I thought it was only the first draft." Considering my status as a university professor, the person begins to doubt her own ability and concurs, "I guess I'd better redo it." In this case, my status had an impact on the dialogue. This is an example where my status was used as a sort of external power to distort the dialogue.

\section{Internal power}

Power can also be located internally in a dialogical process oriented toward reaching understanding. The attempt to reach understanding has intrinsic reasons (i.e., the desire of being understood and of understanding others) (Carspecken, 2003). Interlocutors may feel empowered when such understandings are reached. For example, when my advice to a student is appreciatively accepted, I feel good or powerful. The power here is a kind of affirmation that is internal to the dialogical act. A successful dialogical act is described as powerful or empowering, and such power is desired. This sense of being powerful is not one that requires the state of having power over others.

Though external power and internal power seem antithetical to each other, they are actually intertwined for the former has to be equalized for the latter to occur. Thus, power has a Janus face (Lee, 2009). On the one hand, it is constraining because it deters true consensus from being reached. This is referred to as external power and should be equalized. Power, on the other hand, is generative because it satisfies one's expressive needs and makes one feel empowered. This is called internal power and is empowering. These two senses of power are reconciled in a dialogical paradigm where communication is orientated toward reaching understanding. This is how I see Freire's praxis, which is also dialogical in nature, converges with the concepts of external and internal power. It also lays out a democratic model I advocate and draw on in dealing with the power relations I encounter in collaboration with my students.

\section{Being Disempowered to Empower}

\section{Repositioning Myself}

As an essentialist, I tried to maximize external or coercive power by reducing students, though unknowingly, to knowledge receivers. From the essentialist perspective, I put on myself the pressure of being an omniscient teacher on the one hand. I objectified my students; that is, I regarded them as passive receivers rather than active creators of knowledge on the other hand. I attempted to exercise authority over my students and expected them to agree with me. The problem was that, as a nonnative speaker, I did not consider myself qualified for the authority. Consequently, power viewed slantingly from the external or coercive perspective ignores the full potentiality it can achieve. 
When internal power is brought into the spectrum, one is given an alternative to essentialism. To empower both students and teachers is to minimize as much as possible external or coercive power teachers are tempted to pursue. Teachers have to be disempowered in order to empower. To empower is to lose coercive power first and then assume another kind of power bestowed by an equal peer out of respect and acknowledgement. Teachers and students need each other to feel empowered. Empowerment or maximization of internal power cannot happen without neutralization of external power. Within this reformulated power framework, my students are no longer passive knowledge receivers, but empowered co-researchers. As a nonnative speaker, I can tap into their knowledge as native speakers by inviting them to co-teach and co-research with me.

\section{Form Not Content}

Content was what I, as an essentialist, focused exclusively on. It included knowledge, skills, strategies, techniques, etc. that I wanted to master and pass on to my students. Yet content varies with contexts, time, and people. It is difficult, if not impossible, to master. The more it is focused on, the more likely one will fall into the mindset that education is a top-down banking process.

Form, in contrast, resembles a dialogical structure where teachers and students engage in teaching and learning as a collaborative inquiry. Teachers are not knowledge transmitters but coresearchers. A teacher is what Freire (1984) calls a "teacher-student," and students "studentsteachers" (p. 67). The relationship between teachers and students is not fixed but dynamic and dialogical. What should be fixed or strived for is "form," i.e., a democratic environment where, as discussed previously, internal power is presupposed while external power is minimized.

\section{Rethinking Literacy}

It is not new that literacy should not be defined narrowly to include only skills of reading and writing. A critical view on literacy, which has developed over at least the past few decades, proposes that literacy education should promote the principles of democracy and justice, of questioning and analysis, and of resistance and action (Edelsky, 1999). Therefore, educators should act as social activists and change agents that make an impact on students' learning and even on society as a whole. What is important about the critical turn in literacy education is that there is more educators can teach and learn about literacy than simply reading and writing. Those who are able to read and write are not necessarily critically literate. The critical turn also redefines and broadens educators' role in literacy education. This is where NNES teacher educators can contribute. They can help native speakers examine literacy anew from an outsider's perspective by bringing in a minority's voice that is hardly heard in a dominant group.

In illustration, I would like to briefly recount Joan Wynne's (2002) experience of taking a group of African American high school newspaper staff to a university journalism workshop and award ceremony. Her students were there to learn more about print journalism and to receive an award for one of the ten best high school newspapers. Wynne and her students were sitting in a sea of White faces, listening to one of the media experts talk about ways to improve school newspapers. At the end, the speaker opened the session to questions. One of Wynne's students leaned over to her and whispered, "Here is a list of questions we want you to ask him." Surprised that her student and his cohort were suddenly shy, Wynne said, "No, you ask him." The student replied, "We don't talk right. You ask him." Wynne's story demonstrates the fact that literacy, which might empower minority students, can also serve to marginalize or even silence their 
voices. As insiders of the dominant discourse, native speakers are usually unaware of this political aspect of literacy. Yet NNES teacher educators as outsiders, who have encountered similar experiences in their learning process, can help raise this critical linguistic awareness and sensitivity.

\section{Reconceptualizing Diversity}

Diversity comes to the fore in almost every area including education. Diversity is emphasized in many respects such as culture, language, age, ethnicity, race, religious belief, sexual orientation, etc. However, while diversity in education usually means a diverse student population or a differentiated curriculum that caters to the needs of this population, seldom is attention paid to the diversity of teacher educators. It is imperative that students not only learn about diversity but experience it in the classroom. The interaction with NNES teacher educators is surely helpful in this respect. This is especially important in the light that white pre-service teachers (most of my students are white) are reported to have little cross-cultural knowledge and experience (Gilbert, 1995; McIntyre, 1997; Sleeter, 2000). Yet they still consist of the majority of the teaching force and are likely to run into immigrant/minority students in their teaching careers. Working with a diverse university faculty helps prepare them for a real world where diversity is a fact rather than a hypothesis.

\section{Final Note}

Now that I have told a story of my professional life, it seems incomplete without my personal anecdote. I have a three-year-old daughter. Her name is Penn, which means "hope" in Mandarin Chinese. Penn was born in the United States when I was a doctoral student. My wife and I speak Mandarin Chinese at home, so Penn picks it up quickly. However, in order to play with her friends in the neighborhood, she is also learning English from her playmates, preschoolmates, television, books, etc. Penn enjoys going to a local library, seeing her friend Nemo (a clownfish in the library aquarium) while my wife is looking for books Penn likes to read. In the summer, we usually take her back to our home country Taiwan (In Taiwan, Mandarin Chinese is the official language, and most of the people also speak Taiwanese). Over there, she enjoys being spoiled by Grandpa and Grandma while we, of course, cannot miss out on our favorite food. It seems that she does not care whether she is an American or a Taiwanese. And if you ask her who she is, she will say promptly and firmly, "I am Penn." If you ask me whether Penn is a native English speaker, I will reply, "I don't know," and I don't think it is important. All I know is that she is my daughter, and she is "working the hyphen" - a phrase borrowed from Michelle Fine (1998). She is exploring and traversing two languages and cultures, and she seems to enjoy it.

The dichotomy between native and nonnative in literacy education fails to take into account the complexities and contradictions that define membership in each category. It homogenizes the internal oppositional nature within a group and heterogenizes the overlapping traits between groups. With this problematic dichotomy, we let go of an opportunity to learn from each other by investigating possibilities at the hyphen. We mistaken difference for deficiency (McIntyre, 1997) and thus reify and perpetuate the dichotomy. In fact, one group needs the other to better know itself. Specifically, without nonnativeness, there is incomplete nativeness. The latter has no meaning without the existence and comparison of the former and vice versa. Interdependence and collaboration should, though we are not there yet, characterize the relationship between NNES teacher educators and their NES students on the one hand and between NNES teacher 
educators and their NES colleagues on the other hand. This is especially important as we have an increasingly diverse student population that calls for as diverse talents in our profession to provide an education that fits in with students' individual needs.

Finally, allow me to share a little more of my anecdote before I end this paper. This time, it is about Jack, a six-year-old, native English-speaking, White boy who lives across from us, who usually plays with Penn. One day, Jack came over, smiling. I thought he wanted to play with Penn. He looked shy and said, "Nee How Ma?" which means "How are you?" I was so surprised and said, "Wuo Hen How. Nee How Ma?" (I am very well, and how are you?) Of course, he then had my permission to play with Penn. Now when Penn goes out playing, I know she and other kids as well are not simply yelling and running here and there. They are "playing the hyphen" something I also hope to see in the profession of literacy education.

\section{Notes}

"In 2008, by consensus of its members, the Caucus transformed itself into an Interest Section of the TESOL organizations. Caucuses are mainly for advocacy whereas Interest Sections are more concerned with professional issues" (Braine, 2010, p. 5).

\section{References}

Amin, N. (1997). Race and the identity of the nonnative ESL teacher. TESOL Quarterly, 31(3), 580-583.

Amin, N. (2000). Negotiating nativism: Minority immigrant women ESL teachers and the native speaker construct (Doctoral dissertation, University of Toronto, Canada, 2001).

Dissertation Abstracts International, 61, A 4579.

Bagley, W. C. (1934). Education and emergent man. New York: Ronald Press.

Bagley, W. C. (1938). An essentialist's platform for the advancement of American education. Educational Administration and Supervision, 24, 242-256.

Braine, G. (1999). Non-native educators in English language teaching. Mahwah, NJ: Lawrence Erlbaum.

Braine, G. (2010). Nonnative speaker English teachers: Research, pedagogy, and professional growth. New York and London: Routledge.

Campano, G. (2008). Vignette: Learning to teach by teaching in the margins. In M. Lewison, C. Leland \& J. Harste (Eds.), Creating critical classrooms: $K-8$ reading and writing with an edge (pp. 143-146). New York: Lawrence Erlbaum Associates.

Canagarajah, A. S. (1999). Interrogating the "native speaker fallacy": Non-linguistic roots, nonpedagogical results. In G. Braine (Ed.), Non-native educators in English language teaching (pp. 145-158). Mahwah, NJ: Lawrence Erlbaum.

Carspecken, P. F. (1999). Four scenes for posing the question of meaning and other essays in critical philosophy and critical methodology. New York: Peter Lang.

Carspecken, P. F. (2003). Ocularcentrism, phonocentrism, and the counter enlightenment problematic: Clarifying contested terrain in our schools of education. Teachers College Record, 105(6), 978-1047.

Clandinin, D. J. (2007). Handbook of narrative inquiry: Mapping a methodology. Thousand Oaks, CA: Sage. 
Clandinin, D. J., \& Connelly, F. M. (1994). Personal experience methods. In N. K. Dezin \& Y. S. Lincoln (Eds.), Handbook of qualitative research (pp. 413-427). Thousand Oaks, CA:

Sage.

Clandinin, D. J., \& Connelly, F. M. (1996). Teachers' professional knowledge landscapes: Teacher stories. Stories of teachers. School stories. Stories of schools. Educational Researcher, 25(3), 24-30.

Connelly, F. M., \& Clandinin, D. J. (1990). Stories of experience and narrative inquiry. Educational Researcher, 19(5), 2-14.

Edelsky, C. (1999). Making justice our project: Teachers working toward critical whole language practice. Urbana, IL: National Council of Teachers of English.

Fine, M. (1998). Working the hyphens: Reinventing self and other in qualitative research. In N. K. Denzin \& Y. S. Lincoln (Eds.), The landscape of qualitative research: Theories and issues (pp. 130-155). Thousand Oaks, CA: Sage Publications.

Freire, P. (1984). Pedagogy of the oppressed. New York: Continuum.

Gilbert, S. L. (1995). Perspectives of rural prospective teachers toward teaching in urban schools. Urban Education, 30(3), 290-305.

Habermas, J. (1971). Knowledge and human interests (J. J. Shapiro, Trans.). Boston: Beacon.

Habermas, J. (1984). The theory of communicative action. Volume I: Reason and the rationalization of society (T. McCarthy, Trans.). Boston: Beacon Press.

Habermas, J. (1987). The theory of communicative action. Volume II: Lifeworld and system: A critique of functionalist reason (T. McCarthy, Trans.). Boston: Beacon Press.

Harste, J. (2008). Thought piece: Uncertainty and the teaching of reading and writing. In M. Lewison, C. Leland \& J. Harste (Eds.), Creating critical classrooms: K-8 reading and writing with an edge (pp. 35-37). New York: Lawrence Erlbaum Associates.

Johnston, B. (1997). Do EFL teachers have careers? TESOL Quarterly, 31(4), 681-712.

Kachru, B. B. (1992). Models for non-native Englishes. In B. B. Kachru (Ed.), The other tongue: English across cultures (2nd ed., pp. 48-74). Urbana, IL: University of Illinois Press.

Lee, C. J. (2009, November). The Janus face of power: Foucault versus Habermas. Paper contributed to the Society for the Philosophical Study of Education Conference. Chicago, Illinois.

Liu, J. (1999). Nonnative-English-speaking-professionals. TESOL Quarterly, 33(1), 85-102.

Matsuda, P. K. (2002). Keeping the NNEST movement alive. NNEST Newsletter, 4(2).

Maum, R. (2002). Nonnative-English-speaking teachers in the English teaching profession. ERIC Digest. Retrieved July 31, 2010 from http://www.cal.org/resources/Digest/digest_pdfs/0209maum.pdf.

McIntyre, A. (1997). Making meaning of Whiteness. Albany, NY: State University of New York Press.

Medgyes, P. (1994). The non-native teacher. London: Macmillan Publishers.

Phillipson, R. (1992). Linguistic imperialism. Oxford, UK: Oxford University Press.

Phillipson, R. (1996). ELT: The native speaker's burden. In T. Hedge \& N. Whitney (Eds.), Power pedagogy \& practice (pp. 23-30). Oxford, UK: Oxford University Press.

Shuck, G. (2006). Racializing the nonnative English speaker. Journal of Identity, Language, and Education, 5(4), 259-276.

Sleeter, C. (2000). Multicultural education, social positionality, and whiteness. In E. M. Duarte 
\& S. Smith (Eds.), Foundational perspectives in multicultural education (pp. 118-134). New York: Longman.

Tang, C. (1997). On the power and status of nonnative ESL teachers. TESOL Quarterly, 31(3), 577-580.

Wynne, J. (2002). We don't talk right. You ask him. In L. Delpit \& J. K. Dowdy (Eds.), The skin that we speak: Thoughts on language and culture in the classroom (pp. 203-219). New York: The New Press. 